\title{
The hospital admissions study in England: are there alternatives to emergency hospital admission?
}

Joanna Coast, Abby Inglis, Kieran Morgan, Selena Gray, Max Kammerling, Stephen Frankel

\begin{abstract}
Study objective - To assess the potential for substituting alternative forms of care for admission to an acute hospital in particular groups of patients.

Design - A screening tool, the intensityseverity-discharge review system with adult criteria (ISD-A), developed for hospital utilisation review in the USA, was used in a cohort of hospital admissions to identify a group of patients who could potentially have been treated outside the acute hospital. These patients were further assessed by a panel of general practitioners (GPs) to determine the most appropriate alternative form of care. A cost analysis was performed on the results obtained. Setting - General medicine and geriatric specialties in one acute hospital in the south western region.
\end{abstract}

Patients - Patients comprised a sample of 701 admitted to general medical and geriatric specialties.

Main results - The screening tool identified $19 \cdot 7 \%$ of admissions for whom there was potential for treatment outside the acute hospital. Assessment by the GP panel reduced this potential to between $9.8 \%$ and $15.0 \%$ of emergency admissions. The alternatives most frequently identified as "most appropriate" were the community hospital/GP bed and the urgent outpatient assessment (within either 24 or 48 hours). Potential resource savings based on the average cost were relatively small. This potential seemed to be greater for the alternative of the urgent outpatient assessment.

Conclusions - Potential exists for treating a proportion of patients in lower intensity alternatives to the acute hospital. If this potential were exploited few resource savings would occur.

(f Epidemiol Community Health 1995;49:194-199)

Health authorities and general practitioners purchasing health care are charged with improving the health of their local populations. One way in which this can be achieved is to ensure that health care needs are met in the least resource intensive way, in order to maximise the availability of resources to the population as a whole. Many studies in the past have shown large numbers of both inappropriate hospital admissions (ranging from 15-23\%) and bed days (ranging from $4 \cdot 4 \%-62 \%$ ). ${ }^{1-13}$ It is reasonable to suppose that treatment of these patients with some form of lower intensity care might result in equal benefit to patients while releasing resources for the treatment of others. Testing such hypotheses is particularly important at the present time, when there is general pressure on acute beds and hospitals tend to have difficulty in coping with the level of demand in the winter months.

The hospital admissions study was undertaken with the aim of assessing both admissions to, and stay in, the acute hospital. This paper reports the results of the study of admissions. It was hypothesised at the beginning of the study that the appropriateness of the acute hospital bed in providing the care required by any patient at a given moment partly depends on the availability of, and access to, alternative forms of care. This study aimed particularly to avoid the somewhat loose term "appropriateness", with its pejorative overtones, and to be far more explicit about the categorisation of admissions. Admissions were defined as categories 1 and 2. Category 1 admissions were defined as those for whom there is no alternative to admission to the acute hospital with its high technology facilities. Category 2 admissions were defined as those for whom there may potentially be a lower technology alternative to acute hospital admission.

The general aim of the study of admissions was to assess the potential for substituting alternative forms of provision for care in the acute hospital for particular groups of patients. Within this broad aim there were three specific objectives. The first was to screen a cohort of patients admitted to the hospital in order to classify them into category 1 or 2 . The second specific objective was to find out what the most appropriate alternatives to acute hospital admission might be for those patients classified as category 2 . The third objective was to assess the possible effects on resource use of altering the provision of care to reflect these alternative patterns of care.

\section{Methods}

The hospital admissions study was designed in three phases. The first phase involved the assessment of 700 admissions to the acute hospital on 48 days over a period of six months (November 1992-May 1993). Beginning with a Sunday, all admissions on every fourth fol- 
lowing day were included in the study. The sample size for the study was calculated on the basis that proportions of inappropriate admissions reported in previous studies have varied from $15 \cdot 2-23 \cdot 9 \%{ }^{26}$ The aim was to obtain a sample of at least 100 category 2 admissions for further study, and therefore sample sizes were assessed on the basis of the minimum proportion of $15 \%$. With a sample of 700 individuals it was possible to be $95 \%$ confident that the number of category 2 patients would be between 82 and 120. Either of these limits was felt to be acceptable.

During the first phase of the study, admissions were assessed prospectively on the basis of information from the patient's hospital notes. A trained researcher (AI) applied the intensity-severity-discharge review system with adult criteria (ISD-A) to the patients' notes as a basis for screening admissions for classification into category 1 or category 2 . The ISD-A is a hospital utilisation review tool developed in the USA which assesses the severity of the patient's illness and the intensity of the service they are receiving. It has been validated for use in the USA and has been found to have moderate validity and high reliability. ${ }^{14}$ It is one of a number of tools used routinely for the assessment of hospital utilisation in the USA. The ISD-A was also validated for application in UK research during the hospital admissions study and was found to have moderate validity and high reliability in this context. These results are published elsewhere. ${ }^{15}$

For admissions classified as category 2, a brief abstract containing clinical and social information about the patient was obtained from medical and nursing notes. This included: age; gender; marital status; employment status; type of home; location of home (city/town/suburb/ rural); living with others/living alone; services received in the community; other care received prior to admission; reason for admission (signs and symptoms, including details on examination); past medical history; presumptive diagnosis by GP/referring doctor; presumptive diagnosis on admission by hospital doctor.

An additional part of the first phase was the collection of information from the referring GPs. For all patients whose admission was classified as category 2 , and who were referred to the acute hospital by a GP (as opposed to self or consultant referred), the referring GP was contacted by telephone. During a brief interview the GP was asked whether there had been an alternative form of care they would have preferred to the admission of the patient to hospital. Table 1 List of alternatives to hospital admission used by the general practitioner (GP)

Community hospital/GP bed

Nursing home - immediate access for short term care

Nursing home - immediate access for short term care
Nursing home (EMI) - immediate access for short term care

Nursing home (EMI) - immediate access for short term
Residential home - immediate access for short term care

Residential

Urgent referral for out-patient treatment or investigation - same day (including $x$ ray)

Urgent referral for outpatient treatment or investigation - next day (including $x$ ray)

Intensive home support - provided within 2 hours

Intensive home support - provided within 12 hours

Less intensive home support - provided within 12 hours

Continuous minor social support in the home - provided within 2 hours

Other - to be specified
The second phase of the study involved the further, subjective, assessment of emergency category 2 admissions by a panel of seven GPs. The panel assessed all patients referred by a GP or admitted through the accident and emergency department, but it was considered unreasonable to ask GPs to assess consultant referred patients. The GP panel was recruited to be representative of the various locations within the acute hospital catchment area. The primary aim of the panel was to assess, on the basis of the abstracts described above, whether they considered there was an alternative to acute hospital admission and, if so, the alternative forms of care that might have been made available to these patients. A secondary aim was to contribute to the validity studies reported elsewhere, ${ }^{15}$ and to this end the GP panel also assessed a sample of category 1 admissions.

GPs were asked independently to answer the following question for each admission: "On the basis of this information, was there any alternative form of care which, had it been available at that time, could have prevented the admission to [the acute] hospital?" If GPs answered "no" to this question they were not questioned further for this patient. If the GP answered "yes" to this question, he was then asked to identify the most appropriate alternative form of care from a list of 12 options. This list was devised in conjunction with the members of the panel at a preliminary meeting and is contained in table 1 .

Each abstract was competed by two GPs, with each GP completing 48 abstracts in total. Abstracts were assigned randomly to individual GPs using a partially balanced incomplete block design to ensure that each GP assessed the same number of abstracts, that each abstract was assessed by two GPs, and that each pair of GPs assessed the same number of abstracts. GPs were sent abstracts in batches of six until all abstracts had been completed and returned.

The third phase of the study involved the analysis of the likely effects on resources of adopting alternative forms of care in preference to treatment in the acute hospital. This final phase took the form of a cost analysis in which the costs associated with management in the acute hospital were compared with the costs associated with management via the alternatives identified by the GP panel. It was not possible to perform a full economic evaluation in which the benefits of care in the alternative locations were assessed, given the hypothetical nature of this part of the study, and given that there is no published information available on differences in outcome between locations of care for category 2 (inappropriate) patients.

The cost analysis was designed to compare, from the viewpoint of the NHS, the costs of treating category 2 patients in the acute hospital with the costs of treating these patients in the alternative forms of care identified by the GP panel. For the purpose of the analysis it was assumed that there was only potential for change in those category 2 admissions for 
whom at least one GP had identified an alternative form of care.

Resource use relevant from the viewpoint of the analysis includes both direct costs falling on the hospital and direct costs falling on the GP. The analysis was conducted with a long run perspective - that is, fixed costs such as capital were included. Measures of resource use in the acute hospital (including individuals' length of stay, use of diagnostic tests, and receipt of paramedical services) were taken from the patients' hospital notes. It was not possible to validate this information. Hospital resource use was valued using routine hospital cost data. A number of basic assumptions were made about the costs of alternative forms of care: in particular, it was assumed initially that the length of stay in a GP bed would be the same as that in the acute hospital, and that the many diagnostic test received in the acute hospital would not be received by patients in a GP bed. It was assumed that the time cost to GPs for a community hospital visit would range from $£ 8$ to $£ 12$. The cost of travel to the GP was estimated using a mileage rate of $40 \mathrm{p}$ for a maximum journey of 10 miles. Because of the wide case mix of patients and the hypothetical nature of the alternative forms of care, average specialty costs were used throughout.

A sensitivity analysis was used to show the effects on these cost figures of altering these basic assumptions (such as length of stay in a GP bed and the proportion of patients who woul be admitted to the acute hospital subsequent to an urgent outpatient referral). From the sensitivity analysis it is possible to see how robust the results obtained in the analysis are.

Differences in resource use between particular alternatives were assessed using a paired $t$ test.

\section{Results}

Altogether 701 patients were admitted to the hospital on the 48 days of study enrolment. A full data set was available for $677(96.6 \%)$ of these admissions. A full data set was not available for 24 admissions. For five of these, no data are available. For the remaining 19 ad- missions, 13 patients (68\%) were admitted to general medicine and six (32\%) to geriatrics. Eighteen of these patients were emergency admissions. Four of these emergency admissions were female (22\%), and six were aged over 75 years $(33 \%)$. Although this group of patients differs slightly from the study group, the numbers for whom data were unavailable were small compared to the overall sample.

Of the 677 patients for whom data were available, $68 \%$ were admitted to general medicine and the remaining $32 \%$ were admitted to the specialty of geriatrics. The proportion of admissions to geriatrics in this sample is slightly higher than for overall admissions to the hospital in this year (25\%). A total of $634(94 \%)$ of the admissions were emergencies - that is, they were neither planned/booked or waiting list admissions. As the screening tool, the ISDA, was applicable largely to emergency admissions, only these 634 patients were analysed further. Of these 634 admissions, 322 (51\%) were female, and 263 (41\%) were aged over 75 years.

Of the 634 emergency admissions, 509 $(80.3 \%)$ were classified as category 1 and 125 $(19.7 \%)$ as category 2 . This is consistent with the results obtained in other studies of appropriateness. ${ }^{26} \mathrm{Of}$ the GP referred category 2 admissions $(n=86)$, telephone conversations were subsequently possible with 69 referring GPs, four of whom were unable to comment on the admission. Results were therefore obtained for 65 admissions. For 23 of these 65 admissions (35\%), GPs stated that there was an alternative to hospital admission that they would have preferred.

Altogether 115 of the category 2 admissions were admitted via a GP or the accident and emergency department and so were appropriate for assessment by the GP panel. Abstracts were acquired for $112(97 \cdot 4 \%)$ of these patients. The 112 admissions were studied further by the GP panel during phase 2 of the study. The response rate for the return of abstracts was $100 \%$. Table 2 shows the assessment of abstracts made by GPs.

For 17 out of the 112 admissions both GPs stated that there was no alternative to acute hospital care, and for a further 34 out of the

Table 2 Alternatives to hospital admission in patients identified as category 2 by the ISD-A, as assessed by pairs of general practitioners (GPS). (The table works on the basis of a grid reference, for example, cell $(01,01)$ shows that on 14 occasions both GPs agreed that a GP bed was the most appropriate alternative to care in the acute hospital)

\begin{tabular}{|c|c|c|c|c|c|c|c|c|c|c|c|c|c|}
\hline \multirow{2}{*}{$\begin{array}{l}\text { Alternatives suggested by } \\
\text { second GP }\end{array}$} & \multicolumn{13}{|c|}{ Alternatives suggested by first GP (for code see left hand column) } \\
\hline & 01 & 02 & 03 & 04 & 05 & 06 & 07 & 08 & 09 & 10 & 11 & 12 & $A$ \\
\hline $\begin{array}{l}01 \text { - GP bed } \\
02 \text { - Nursing home } \\
03 \text { - Nursing home EMI } \\
04 \text { - Residential home } \\
05 \text { - Hospice } \\
06 \text { - OPA }(24 \mathrm{~h}) \\
07 \text { - OPA }(48 \mathrm{~h}) \\
08 \text { - Int home }(2 \mathrm{~h}) \\
09 \text { - Int home }(12 \mathrm{~h}) \\
10 \text { - Less int home } \\
11 \text { - Cont minor } \\
12 \text { - Other } \\
A \text { - Acute }\end{array}$ & 14 & $\begin{array}{l}4 \\
1\end{array}$ & $\begin{array}{l}0 \\
0 \\
0\end{array}$ & $\begin{array}{l}1 \\
0 \\
0 \\
0\end{array}$ & $\begin{array}{l}1 \\
0 \\
0 \\
0 \\
0\end{array}$ & $\begin{array}{r}3 \\
0 \\
0 \\
0 \\
0 \\
11\end{array}$ & $\begin{array}{l}2 \\
0 \\
0 \\
0 \\
0 \\
5 \\
0\end{array}$ & $\begin{array}{l}3 \\
1 \\
0 \\
0 \\
0 \\
0 \\
0 \\
0\end{array}$ & $\begin{array}{l}2 \\
1 \\
0 \\
0 \\
0 \\
0 \\
0 \\
0 \\
0\end{array}$ & $\begin{array}{l}2 \\
0 \\
0 \\
0 \\
0 \\
0 \\
0 \\
0 \\
0 \\
0\end{array}$ & $\begin{array}{l}1 \\
0 \\
0 \\
0 \\
0 \\
0 \\
0 \\
0 \\
0 \\
0 \\
0\end{array}$ & $\begin{array}{l}1 \\
2 \\
0 \\
0 \\
0 \\
1 \\
1 \\
0 \\
0 \\
0 \\
1 \\
3\end{array}$ & $\begin{array}{r}12 \\
3 \\
0 \\
0 \\
1 \\
10 \\
3 \\
1 \\
0 \\
0 \\
0 \\
4 \\
17\end{array}$ \\
\hline
\end{tabular}

ISD-A = intensity-severity-discharge review with adult criteria.

OPA = outpatient appointment; Int home = intensive home support

OPA = outpatient appointment; Int home = intensi 
Table 3 Decision rules used to collapse the set of alternatives to hospital admission

(1) Where results were used for the maximum potential for change it was assumed that acute hospital admission was the chosen option, only if both GP's had chosen the option of acute care.

(2) When option chosen option if either of the two GPs had chosen the option of acute care.

(3) Where the option of acute care was not chosen, the remaining alternatives were allocated to either "same day outpatient assessment" or to "GP bed".

(4) The choice of "same day outpatient assessment" or "next day outpatient assessment" where chosen by one GP would The choice of "same day outpatient assessment" or "next day outpatient assessment" where chosen by one GP would
always take precedence over the choice of "GP bed" (or equivalent) on the basis that this provides high technology rather always take precedence over the choice of "GP bed" (or equivalent) on the basis that this provides high techn
than low technology care, and allows for subsequent admission to either the acute or community hospital.

(5) All "next day outpatient assessment" choices were recorded as "same day outpatient assessment" on the grounds that the latter is more intensive.

(6) All remaining options, which essentially provide nursing care of some description, would be recorded as the most intensive alternative: "GP bed".

(7) Where data were missing for one GP, the option was classified as the choice of the remaining GP, subject to the decision rules above.

Table 4 Summary of potential alternatives to hospital admission following the use of decision rules to collapse data. Extrapolation to annual admissions to general medicine/geriatrics in the study hospital are also shown

\begin{tabular}{|c|c|c|c|c|c|c|}
\hline & \multicolumn{3}{|c|}{ Maximum potential for use of alternatives } & \multicolumn{3}{|c|}{ Minimum potential for use of alternatives } \\
\hline & $\begin{array}{l}\text { No in } \\
\text { study }\end{array}$ & $\begin{array}{l}\text { Extrapolation to } \\
\text { annual figures }\end{array}$ & $\begin{array}{l}\% \text { of annual } \\
\text { admissions }\end{array}$ & $\begin{array}{l}\text { No in } \\
\text { study }\end{array}$ & $\begin{array}{l}\text { Extrapolation to } \\
\text { annual figures }\end{array}$ & $\begin{array}{l}\% \text { of annual } \\
\text { admissions }\end{array}$ \\
\hline $\begin{array}{l}\text { Community hospital } \\
\text { Same day outpatient assessment } \\
\text { Acute hospital }\end{array}$ & $\begin{array}{l}59 \\
36 \\
17\end{array}$ & $\begin{array}{l}449 \\
274\end{array}$ & $\begin{array}{l}8 \cdot 4 \\
5 \cdot 1\end{array}$ & $\begin{array}{l}38 \\
23 \\
51\end{array}$ & $\begin{array}{l}297 \\
175\end{array}$ & $\begin{array}{l}5 \cdot 6 \\
3 \cdot 3\end{array}$ \\
\hline Total & 112 & & & 112 & & \\
\hline
\end{tabular}

112 one of the two GPs stated that there was no alternative to acute hospital care. On 61 occasions, however, both GPs agreed that an alternative to acute hospital care existed - although they may have disagreed on the precise alternative that would have been most appropriate. Table 2 shows, interestingly, that GPs choices are concentrated particularly in the areas of the GP bed (01) and the urgent outpatient assessment $(06,07)$.

While the table shows interesting results, it is difficult to utilise in practice, given the varied nature of the responses. In order to proceed to the cost analysis, the alternatives to hospital admission selected by the GP panel were collapsed into two main alternatives using a number of clear decision rules shown in table 3 . Because of the concentration on the GP bed and the urgent outpatient assessment as alternatives to admission, these were the alternatives considered further.

By using the fact that two GPs had independently assessed each patient, it was possible to derive a range for the potential for alternatives to admission. There was considered to be maximum potential for change if it was assumed that the patient only required care in the acute hospital when both GPs stated this was the case, and that there was a minimum potential for change if it was assumed that the patient required care in the acute hospital even when just one of the two GPs stated that this was the case. This is arguably more useful than

Table 5 Resource savings per admission from potential alternatives to hospital admission

\begin{tabular}{|c|c|c|c|c|}
\hline \multirow{2}{*}{$\begin{array}{l}\text { GP beds: } \\
\text { Acute hospital cost } \\
\text { GP bed cost } \\
\text { Cost difference }\end{array}$} & \multicolumn{2}{|c|}{$\begin{array}{l}\text { Maximum potential for } \\
\text { use of alternatives } \\
(\mathscr{)})\end{array}$} & \multicolumn{2}{|c|}{$\begin{array}{l}\text { Minimum potential for } \\
\text { use of alternatives } \\
(£)\end{array}$} \\
\hline & $\begin{array}{r}1366 \cdot 7 \\
1272 \cdot 15 \\
94 \cdot 62\end{array}$ & $\mathrm{p}=0.0057$ & $\begin{array}{r}1431 \cdot 23 \\
1384 \cdot 07 \\
47 \cdot 16\end{array}$ & $\mathrm{p}=0.17$ \\
\hline $\begin{array}{l}\text { Urgent outpatient: } \\
\text { Acute hospital cost } \\
\text { Urgent outpatient cost } \\
\text { Cost difference }\end{array}$ & $\begin{array}{l}931 \cdot 12 \\
172 \cdot 45 \\
758 \cdot 67\end{array}$ & $\mathrm{p}=0.0048$ & $\begin{array}{r}1244 \cdot 59 \\
195 \cdot 35 \\
1049 \cdot 24\end{array}$ & $\mathrm{p}=0.0001$ \\
\hline
\end{tabular}

obtaining a consensus given that, in practice, there will always be differences of opinion among GPs about the potential for substituting alternatives.

The data in table 4 show that between 61 and 95 of the $634(9 \cdot 6-15 \%)$ acute hospital admissions could, with the provision of alternative forms of care, have been avoided. Extrapolations of these data to annual admissions are also shown in table 4 . The cost analysis, phase 3 of the study, was based on the data contained in table 4 .

Information about resource use was available for 96 of the 112 category 2 patients, although not all this information was used as some admissions were not assigned an alternative by the panel. Data about the resources used in treating these patients were combined with information about costs obtained from the hospital to produce costs per admission. The results shown in table 5 were obtained.

The costs of admission were then combined with the expected number of admissions which might be saved each year, to obtain an estimate of the resource savings that might be available in the long run from an annual reduction in admissions on the scale estimated in phase 2 . For the alternative of the GP bed, the potential for resource savings was relatively modest, with a maximum potential for resource saving of $£ 42484(n=449)$, and a minimum potential for savings of $£ 14007$. There seems to be a greater potential for savings from the urgent outpatient assessment of a maximum of $£ 207875 \quad(n=274)$ and a minimum of $£ 183617$.

A sensitivity analysis was performed to test the impact of altering assumptions about the cost of a GP consultation, the length of stay which would occur in a GP bed, and the level of subsequent admissions which would result from an urgent outpatient assessment. The results of the sensitivity analysis are shown in table 6. The basic assumptions used in the original analysis are also shown in the table. 
Table 6 Sensitivity analysis of potential annual resource savings from using alternatives to acute hospital admission. The effects on the potential for resource savings of using different assumptions are compared with the results obtained using the basic assumptions from which the analysis began

\begin{tabular}{|c|c|c|}
\hline & $\begin{array}{l}\text { Maximum potential for } \\
\text { use of alternatives }(n=449) \\
(£)\end{array}$ & $\begin{array}{l}\text { Minimum potential for } \\
\text { use of alternatives }(n=297) \\
(£)\end{array}$ \\
\hline \multicolumn{3}{|l|}{ Community hospital cost: } \\
\hline $\begin{array}{l}\text { Basic assumption } \\
\text { (GP consultation }=£ 12, \mathrm{LoS}=\text { acute })\end{array}$ & 42484 & 14007 \\
\hline $\begin{array}{l}\text { Alternative assumption } 1 \\
\text { (GP consultation }=f 16, \mathrm{LoS}=\text { acute) }\end{array}$ & 22190 & -600 \\
\hline $\begin{array}{l}\text { Alternative assumption } 2 \\
\text { (GP consultation }=f 12, \operatorname{LoS}=\text { acute }+10 \% \text { ) }\end{array}$ & -14637 & -27101 \\
\hline $\begin{array}{l}\text { Alternative assumption } 3 \\
(\mathrm{GP} \text { consultation }=£ 16, \mathrm{LoS}=\text { acute }+10 \%)\end{array}$ & -36962 & -43166 \\
\hline \multicolumn{3}{|l|}{ Urgent outpatient cost: } \\
\hline $\begin{array}{l}\text { Basic assumption } \\
\text { (no subsequent admissions) }\end{array}$ & 207875 & 183617 \\
\hline $\begin{array}{l}\text { Alternative assumption } 1 \\
\text { (30\% subsequent admissions) }\end{array}$ & 142395 & 126539 \\
\hline $\begin{array}{l}\text { Alternative assumption } 2 \\
\text { ( } 60 \% \text { subsequent admissions) }\end{array}$ & 76917 & 69465 \\
\hline $\begin{array}{l}\text { Alternative assumption } 3 \\
\text { ( } 90 \% \text { subsequent admissions) }\end{array}$ & 11436 & 12388 \\
\hline
\end{tabular}

LoS $=$ length of stay

The results show that as the assumptions are relaxed and become less favourable, the potential savings become much smaller, and in some cases are negative.

\section{Discussion}

The results obtained point to potential for substituting lower intensity care for higher intensity care for $10-15 \%$ of all admissions to general medicine and geriatrics. This result is based on initial application of the ISD-A and the assessments made by the GP panel; application of the ISD-A resulted in $20 \%$ of admissions being considered to be category 2, but assessment by the GP panel reduced this by between one quarter and one half. This may reflect the known tendency of the ISD-A, as with other objective instruments, to overestimate the proportion of "inappropriate" patients. ${ }^{14}$ It is important to note that the potential for altering care noted here depends on both the ISD-A and at least one GP assigning the category 2 classification to an admission. Thus both objective measures, and more intuitive clinical decision making have been used in arriving at the final estimates of potential for change.

Although not a formal test of validity, the results of the concurrent telephone survey of all admitting GPs for category 2 patients support the results obtained from the GP panel. This telephone survey showed that $35 \%$ of admitting GPs would have preferred an alternative form of care for their patient at the time of admission, had that alternative been available. These admitting GPs had not had the benefit of the extensive discussions that the GP panel received, and so the extent of their agreement with the results obtained is of particular note.

It was interesting to note the alternatives chosen most frequently by the panel were those of the GP bed and urgent outpatient assessment. Although panel members had, at the prior meeting, been keen to include the many home support alternatives, these were seldom chosen in practice. This may be because the
GPs on the panel had little practical experience of using such alternatives.

Many of the difficulties in interpreting the data reported here relate to the cost analysis. In particular, the data are based on average rather than marginal costs. Had the data been based on marginal costs, it is likely that the resource savings seen would have been smaller or non-existent. This is because of the relatively high proportion of fixed costs in any hospital, and the extra costs which would be incurred by increasing provision of community hospital care and same-day outpatient assessments. Increasing GP beds may involve high capital costs, particularly where there are already high occupancy rates in community beds. Where GP beds can be located on existing sites these costs may be lower. GP referral rates may, however, be lower than if community hospital beds are distributed more widely within a district, given that GPs based further from the acute hospital will be less likely to admit patients to GP beds.

There may also be greater opportunity costs associated with management of patients by outpatient assessment than implied here. Such provision would involve increased consultant or other senior staff availability, particularly out of hours. It should be pointed out, however, that extra medical staff assessment is likely to be minimal - an average extra number of assessments of between 0.48 and 0.75 per day.

The data reported here indicate that resource savings are more likely to occur as a result of redirecting care towards the urgent outpatient assessment than by increasing numbers of GP beds. This conclusion is supported by the results obtained in the sensitivity analysis, which demonstrates that any assumptions other than the most favourable lead to a higher cost for GP beds than for acute hospital beds. While the data used in the analysis are imperfect, and in particular relate mainly to average costs, this result is relatively consistent across the various analyses.

The generalisability of these results will depend in large part on the current availability of alternative forms of care in other health dis- 
tricts. This will affect both the potential for changing patterns of care and the relative resource effects. For example, the costs were calculated from data obtained in an area where community hospital provision is relatively limited, with high occupancy rates. Where there is greater availability of community beds, the potential for altering patterns of care in this direction may be less than this study has shown. Where potential exists, however, the opportunity costs associated with altering the pattern of care may be much reduced if there is unused capacity in the community hospital.

The outcome of the care provided to patients in any particular location was beyond the scope of this study, given the varied nature of problems for which people were admitted and the lack of routine outcome data. No allowance could be made for differences in outcome which might result from alternative locations of care. It is vital, therefore, to stress that the results reported here consider only one half of the equation. The inputs to health care are considered, but any changes in the output of health remain unaccounted for. Given the potential for change identified in this study, assessments of the marginal benefits, as well as the marginal costs, associated with changes in the pattern of care are now required.

This study has identified potential for altering the balance of care away from the acute hospital. Between 10 and $15 \%$ of emergency general medical and geriatric admissions could be treated as, or more, appropriately in alternative forms of care to the acute hospital. This result is robust in that it depends on objective measurement combined with the more intuitive aspects of clinical decision making.

The study is more equivocal, however, in the support that it provides for shifting resources away from acute hospital provision and towards less intensive alternatives on the basis of saving resources. Substantial resources will be saved only if the marginal costs of treating patients in the acute hospital are of the same order as the average costs used in the analysis, and if the more favourable of the assumptions used reflect reality. If the less favourable assumptions are correct, the potential for resource saving is likely to be very limited. It is by no means certain, therefore, that a movement of resources away from the acute hospital will improve the efficiency of the NHS.

We thank, for assistance, Tim Peters, Senior Lecturer in Medical Statistics; the seven GPs who made up the GP panel; clinicians, nursing, and administrative staff in the acute hospital; members of the finance department in the acute hospital. We would also like to acknowledge the helpful comments of the two referees.

1 Anderson P, Meara J, Brodhurst S, Attwood S, Timbrell M, Gatherer A. Use of hospital beds: a cohort study of admissions to a provincial teaching hospital. BMF 1988; 297:910-12.

2 Beech R, Challah S, Ingram RH. Impact of cuts in acute beds on services for patients. BMF 1987;294:685-8.

3 Mackintosh JM, McKeown T, Garratt FN. An examination of the need for hospital admission. Lancet 1961;i:815-18. Murphy FW. Blocked beds. BMF 1977;1:1395-6.

5 Rosser RM. The reliability and application of clinical judgment in evaluating the use of hospital beds. Med Care ment in evaluating

6 Torrance N, Lawson JAR, Hogg B, Knox JDE. Acute admissions to medical beds. $\mathcal{F} R$ Col Gen Pract 1972;22 211-19.

7 Farag RR, Tinker GM. Delay in discharge of patients from an acute geriatric unit. Health Trends 1985;17:41.

8 Maguire PA, Taylor IC, Stout RW. Elderly patients in acute medical wards: factors predicting length of stay in hospital. BMF 1986;292:1251-3.

9 Coid J, Crome P. Bed blocking in Bromley. BMf 1986;292. 1253-6.

10 Namdaran F, Burnet C, Munroe S. Bed blocking in Edinburgh Hospitals. Health Bull 1992;50:223-27.

11 McArdle C, Wylie JC, Alexander WD. Geriatric patients in an acute medical ward. $B M F$ 1975;4:568-9.

12 Moore W. Can you stop the bed-block jam? Healthcare Management 1993;March:14-16.

13 Victor C, Nazareth B, Hudson M, Fulop N. The in appropriate use of acute hospital beds in an inner London District Health Authority. Health Trends 1993;25(3):94 97.

14 Strumwasser I, Paranjpe NV, Ronis DL, Share D, Sell LJ. Reliability and validity of utilisation review criteria. Med Care 1990;28(2):95-111.

15 Inglis A, Coast J, Gray SF, Peters TJ, Frankel SJ. Appropriateness of hospital utilisation: the validity and reliability of the intensity-severity-discharge review system (ISD-A) in a UK acute hospital setting. Med Care (in press). 